\title{
Death and dying during the pandemic
}

\author{
New expressions of humanity help dispel fear and protect the mental health of bereaved families
}

\author{
Sarah Yardley consultant in palliative medicine ${ }^{1}$, Martin Rolph member of the public with experience \\ of emergency and end-of-life care ${ }^{2}$
}

${ }^{1}$ Palliative Care Department, Central and North West London NHS Foundation Trust, London, UK; ${ }^{2}$ Cardiff, UK

Covid-19 has rapidly forced utilitarian priorities to dominate decision making. As basic freedoms are restricted, individuals are being asked to make sacrifices for the collective good, including profound changes in how we care for people who are dying and those they leave behind.

Hospitals have closed their doors to visitors, separating patients from family and friends. For patients with covid-19 there is little time to adjust to the possibility of death since deterioration is rapid and death typically occurs no more than 2-3 days after a decision not to offer or to withdraw intensive care support.

Reports of families denied access to patients dying from covid-19, refusals to release bodies, and restrictions on funerals are widespread. ${ }^{12}$ Some hospitals are allowing one asymptomatic visitor for patients at the end of life, providing they do not need to self-isolate and can wear appropriate personal protective equipment (PPE). But practice is inconsistent and international consensus is lacking.

Bereavement services are delivered with as little human contact as possible. Infection risks have stopped viewings in hospital mortuaries, and deaths are no longer registered in person. Governments together with faith leaders have developed guidance for safe funerals, ${ }^{3}$ including restrictions on the number and relationship of mourners, and those allowed to conduct rituals requiring close contact with the body. These restrictions conflict with collective and symbolic responses to a person's death usually enacted to demonstrate the endurance of society and its values. ${ }^{4-6}$

Dying alone or leaving a death unmarked is a major societal wrong, ${ }^{7}$ as evidenced by the emotional labour expended by professionals when bearing witness in the absence of family or friends. ${ }^{7}$ This is a testament to our collective belief in the need for humanity at the end of life, and it is highly valued by many families in the current situation. ${ }^{8}$

\section{Greatest fears}

The greatest fears of people unable to be with a loved one dying from covid-19 include basic care not being given; no one being there to tell caregivers what the patient is "really like"; decisions not being made on just grounds; and that the patient might die in pain. Listening, empathising, and taking the time to care are often more gratefully received than clinical explanations (although these are also important). Many relatives are further reassured by evidence of the care that professional teams show to each other.

We must ensure that humanity, community, and compassion at the end of life are sustained within the new and still changing ways of working. Feeling safe (not just being technically safe) is important for patients, relatives, and staff. ${ }^{9}$

Time spent developing appropriate, flexible, approaches to death and bereavement during the pandemic will more than repay the investment. Examples might include identifying people who could be quickly trained in PPE and clear communication methods to liaise between healthcare professionals and families if clinician time is short or putting in place transparent measures to ensure that patients will not die alone if restrictions or limited supplies of PPE prevent visits.

Acting now to create new expressions of humanity at the end of life may prevent some of the downstream harms to mental health and wellbeing associated with the "difficult death" of a loved one and the complicated bereavement that may follow. ${ }^{10}$ We can do this by helping people who are unlikely to survive covid-19 to make informed choices about whether they want admission to hospital, including sharing information about what happens on admission and community alternatives available; initiating discussions soon after hospital admission about advance care planning and treatment escalation; and ensuring parallel planning when survival is uncertain, offering supportive care and symptom control alongside treatment interventions.

Technological solutions to communication between patients and families should be supported - through encouraging videocalls and reminders to bring phones and chargers on admission—with families given clear daily updates (good frameworks are available ${ }^{11}$ ), including discussing the possibility of dying. And we should make sure no one dies alone, engaging chaplaincy support if desired and PPE guidelines permit. 
We must also take care with the language we use. Ambiguous terms such as "ceiling of care" should be avoided—care is always given, even when a patient's interventional treatment plan reaches its limit.

Finally, it is important to acknowledge that we too are human. We must look for signs of compassion fatigue in our colleagues and support each other. Sharing experiences and listening to patients, their loved ones, and our colleagues will enable us to create new ways to help people know that every death is consciously witnessed; that each of those who died mattered.

Competing interests: We have read and understood BMJ policy on declaration of interests and have no relevant interests to declare.

Provenance and peer review: Commissioned; not externally peer reviewed.

1 Booth R, Pidd $\mathrm{H}$. UK hospitals tightening restrictions on visits - even to dying patients. Guardian 2020 Mar 30. https://www.theguardian.com/world/2020/mar/30/uk-hospitalstightening-restrictions-on-visits-even-to-dying-patients-coronavirus

2 How covid-19 is changing funerals. Economist $2020 \mathrm{Apr} 11$. https://www.economist.com/ britain/2020/04/11/how-covid-19-is-changing-funerals
3 Public Heath England. Guidance for care of the deceased with suspected or confirmed coronavirus (COVID-19), 2020. https://www.gov.uk/government/publications/covid-19guidance-for-care-of-the-deceased/guidance-for-care-of-the-deceased-with-suspectedor-confirmed-coronavirus-covid-19

4 Van Gennep A. The rites of passage. University of Chicago Press, 1960

5 Bloch M, Parry JK, eds. Death and the regeneration of life. Cambridge University Press, $198210.1017 /$ CBO9780511607646.

6 Long SO, Buehring S. Searching for life in death: Celebratory mortuary ritual in the context of US interfaith families. Mortality 2014;19:80-100. 10.1080/13576275.2013.870985.

7 Bailey T, Walter T. Funerals against death. Mortality (Abingdon) 2016;21:149-66. 10.1080/13576275.2015.1071344. 27019605

8 Turner N. A relative absence: exploring professional experiences of funerals without a congregation. British Sociological Association Social Aspects of Death, Dying and Bereavement Study Group annual symposium: death and relationships. Sheffield, $5 \mathrm{Dec}$ 2019.

9 Collier A, Sorensen R, ledema R. Patients' and families' perspectives of patient safety at the end of life: a video-reflexive ethnography study. Int J Qual Health Care 2016;28:66-73. 10.1093/intqhc/mzv095. 26668105

10 Compassion in Dying. Coronavirus: making decision about treatment. https://coronavirus. compassionindying.org.uk/making-decisions-about-treatment/

11 VITAL talk. Covid ready communication playbook 2019. https://www.vitaltalk.org/guides/ covid-19-communication-skills/

12 Field-Smith A, Robinson L. Talking to relatives: a guide to compassionate phone communication during covid-19, 2019. https://twitter.com/DrAntoniaFS/status/ $1246162643158798337 ? \mathrm{~s}=20$

Published by the BMJ Publishing Group Limited. For permission to use (where not already granted under a licence) please go to http://group.bmj.com/group/rights-licensing/ permissions 